\title{
The context dependence of non-consumptive predator effects
}

\author{
Aaron Wirsing ${ }^{1}$, Michael Heithaus ${ }^{2}$, Joel Brown ${ }^{3}$, Burt Kotler ${ }^{4}$, and Oswald Schmitz ${ }^{5}$ \\ ${ }^{1}$ University of Washington \\ ${ }^{2}$ Florida International University \\ ${ }^{3}$ University of Illinois at Chicago \\ ${ }^{4}$ Ben-Gurion University of the Negev \\ ${ }^{5}$ Yale University
}

April 28, 2020

\begin{abstract}
Non-consumptive predator effects (NCEs) are now widely recognized for their capacity to shape ecosystem structure and function. Yet, forecasting the propagation of these predator-induced trait changes through particular communities remains a challenge, in part because we lack a predictive framework that accounts for environmental and species context. Accordingly, focusing on plasticity in prey anti-predator behaviors, we conceptualize the multi-stage process by which predators trigger direct and indirect NCEs, review and then distill potential drivers of NCE contingencies into three key categories (properties of the prey, predator, and setting), and conduct a meta-analysis to quantify the extent to which prey behavioral plasticity in response to predation risk hinges on a well-studied driver - prey energetic state. Our synthesis underscores the myriad factors that can generate NCE contingencies while guiding how research might better anticipate and account for them. We highlight two key knowledge gaps that continue to hinder development of a comprehensive framework for exploring non-consumptive predator-prey interactions. These are insufficient exploration of 1) context-dependent indirect NCEs and 2) the ways in which direct and indirect NCEs are shaped interactively by multiple drivers of context dependence.
\end{abstract}

\section{REVIEW AND SYNTHESIS}

The context dependence of non-consumptive predator effects

Aaron J. Wirsing ${ }^{1}$, Michael R. Heithaus ${ }^{2}$, Joel S. Brown ${ }^{3,4}$, Burt P. Kotler ${ }^{5}$, Oswald J. Schmitz ${ }^{6}$

${ }^{1}$ School of Environmental and Forest Sciences, Box 352100, University of Washington

Seattle, WA 98195, USA, wirsinga@uw.edu (corresponding author)

${ }^{2}$ Department of Biological Sciences, Marine Sciences Program, 3000 NE 151st St, Florida International University, North Miami, FL 33181, USA, heithaus@fiu.edu

${ }^{3}$ Department of Biological Sciences, University of Illinois at Chicago, 845 West Taylor Street, Chicago, IL 60607, USA, squirrel@darwiniandynamics.org

${ }^{4}$ Department of Integrated Mathematical Oncology, Moffitt Cancer Center, 12902 Magnolia Dr., Tampa, FL, 33613 , USA

${ }^{5}$ Mitrani Department of Desert Ecology, Jacob Blaustein Institutes for Desert Research

84990 Midreshet, Ben-Gurion University of the Negev, Ben-Gurion, Israel, kotler@bgu.ac.il

${ }^{6}$ School of Forestry and Environmental Studies, Yale University, 195 Prospect Street, New Haven, CT 06511, USA, Oswald.schmitz@yale.edu 


\section{Running head: Context dependence of NCEs}

Statement of authorship : AW and MH conceived of the idea for the paper, and AW performed the metaanalysis. All authors wrote the manuscript as a team and contributed substantially to revisions.

Data accessibility statement : Should the manuscript be accepted, the data supporting the results will be archived in the dryad digital repository.

Counts : Abstract (184); Main text (7495); Cited references (164); Tables (0); Figures (4); Text boxes (3)

Key Words : anti-predator behavior; contingency; energetic state; meta-analysis; predation risk; predatorprey interactions; risk effects; state-dependence; top-down effects; trade-offs

Abstract. - Non-consumptive predator effects (NCEs) are now widely recognized for their capacity to shape ecosystem structure and function. Yet, forecasting the propagation of these predator-induced trait changes through particular communities remains a challenge, in part because we lack a predictive framework that accounts for environmental and species context. Accordingly, focusing on plasticity in prey anti-predator behaviors, we conceptualize the multi-stage process by which predators trigger direct and indirect NCEs, review and then distill potential drivers of NCE contingencies into three key categories (properties of the prey, predator, and setting), and conduct a meta-analysis to quantify the extent to which prey behavioral plasticity in response to predation risk hinges on a well-studied driver - prey energetic state. Our synthesis underscores the myriad factors that can generate NCE contingencies while guiding how research might better anticipate and account for them. We highlight two key knowledge gaps that continue to hinder development of a comprehensive framework for exploring non-consumptive predator-prey interactions. These are insufficient exploration of 1) context-dependent indirect NCEs and 2) the ways in which direct and indirect NCEs are shaped interactively by multiple drivers of context dependence.

\section{Introduction}

The idea that predators might influence prey non-consumptively by eliciting trait changes has a long history. Indeed, Darwin (1839) hypothesized that prey escape responses cost time and energy to maintain and, consequently, should attenuate in the absence of predators. Today, these predator-induced trait changes, or non-consumptive effects (NCEs), have a strong conceptual basis (Charnov et al . 1976; Lima \& Dill 1990; Lima 1998, Creel \& Christianson 2008) and are thought to rival or even exceed direct predation in terms of their impacts on prey populations and ecosystems (Kotler \& Holt 1989; Peacor \& Werner 2001; Werner \& Peacor 2003; Schmitz et al . 2004; Preisser et al . 2007). Once the purview of laboratory and short-term field experiments involving small-bodied taxa (Kotler 1984; Preisser et al . 2005; Weissburg et al . 2014), NCEs and their broader consequences are increasingly being explored in large vertebrate systems (e.g., Dill et al . 2003; Willems \& Hill 2009; Burkholderet al . 2013; Middleton et al . 2013; Basille et al . 2015; Moll et al . 2016; Le Roux et al . 2018; Courbinet al . 2019; Smith et al . 2019; Valeix et al . 2019). This expansion has shed new light on the extent to which NCEs scale up to communities of larger-bodied species. Yet, it has also drawn more attention to contingencies in NCEs. Such contingencies currently defy a coherent explanation, underscoring the need for standardized methodology for evaluating these phenomena across species and environmental contexts (Ford \& Goheen 2015; Prugh et al . 2019) and conceptual clarity (Schmitz et al . 2017a; Gaynor et al . 2019) to guide research.

A growing literature suggests that contingency in NCEs hinges on key properties of the organisms involved as well as the environments in which they interact (Preisser et al . 2007; Heithaus et al . 2009; Wirsing et al . 2010; Creel 2011; Schmitz \& Trussell 2016). Accordingly, there have been several recent calls for these properties to be characterized and incorporated into a general framework for predicting the nature and consequences of NCEs within ecological communities (e.g., Cresswell 2008; Heithaus et al . 2009; Creel 2011; Moll et al . 2017). Here, to facilitate the development of such a framework, we (i) conceptualize the multi-stage process by which predators may trigger direct and indirect NCEs; (ii) review key drivers of context dependence in NCEs; and (iii) quantify the extent to which prey trait plasticity in response to predation risk hinges on prey energetic state to demonstrate how considerations of contingency are critical 
to understanding the role of NCEs in complex communities. We then (iv) conclude with a synthesis and prospectus for future work. Our review spans aquatic and terrestrial ecosystems, addresses invertebrates and vertebrates, and focuses on a prevalent form of prey trait plasticity that is often implicated in the transmission of NCEs, anti-predator behaviors. We emphasize, however, that many of the sources of context dependencies that we address likely also apply to other forms of predator-induced trait modification (e.g., prey development, morphology, and physiology).

\section{Propagation of NCEs in communities}

Predation risk is typically defined as the probability of an individual becoming prey within a given place and time (Lima \& Dill 1990). However, predation risk could just as easily be conceptualized as the probability of an individual becoming prey at a given place and time assuming no, or some set amount of, anti-predator investment (Lank \& Ydenberg 2003). Predation risk under the former definition is more intuitive, given its direct link to observable patterns of mortality, and therefore lends itself to estimation via the combination of spatiotemporal probabilities of encountering and being killed by predators (Lima \& Dill 1990; Lima 1992). Estimates of risk based on this definition reflect inherent properties of the location and time of interest and dynamic properties of the predator (e.g., decisions about whether to attack in response to prey behavior) and the prey (e.g., defensive investment). Accordingly, we view them as measures of realized predation risk - By contrast, predation risk under the latter definition, termed intrinsic predation risk ordanger , is harder to measure because it is an abstract construct (Lank \& Ydenberg 2003). Nevertheless, this latter conceptualization importantly decomposes the process by which prey individuals experience and respond to the threat of predation into a series of steps beginning with exposure to risk stimuli and ending with changes to prey numbers and traits (e.g., behavior) that may affect additional species within the community (Fig. 1 ). Consequently, it provides a clearer mechanistic basis for understanding when and how various sources of contingency might direct the propagation of NCEs through communities than does the former definition. Hence, while acknowledging the validity of both approaches to defining predation risk, we focus on intrinsic risk for the remainder of our review.

Propagation of NCEs consists of three phases (Fig. 1 ) within a context of intrinsic risk. Every point in space and time is characterized by some value of intrinsic predation risk, which includes spatial properties of the situation that influence the likelihood of predator-induced mortality but that prey cannot easily modify through behavioral changes. These properties include availability of refuges, presence of escape impediments, dilution of risk by conspecifics and by other species, and the abundance of predators and species that might inhibit predator effectiveness (Lank \& Ydenberg 2003). Collectively, they are often viewed as determinants of the background pattern of risk for a given location. Areas with elevated background risk are sometimes called risky places (Creel et al . 2008). Intrinsic risk is also influenced temporally by whether predators, and other species or environmental conditions (e.g., moonlight) that might influence the predator's efficacy, are currently present at a location. Periods when the presence of predators or conditions heighten prey vulnerability are considered to be risky times (Creel et al . 2008).

Within the setting of intrinsic risk, phase one concerns whether the forager perceives any cues related to the current level of intrinsic risk. Prey may either detect spatiotemporal cues that reflect intrinsic predation risk (including an attack itself), setting up the possibility of NCEs, or fail to detect appropriate risk stimuli, in which case no NCEs will result (from the cue in question) and mortality from the predator will be more likely. Thus, factors influencing prey detection of intrinsic risk cues may operate as key sources of context dependencies in NCEs.

Foragers that perceive intrinsic cues can then respond to them in phase two. Perceived danger may or may not elicit a prey response of sufficient magnitude to precipitate a NCE. In response to background risk and risky times, prey individuals may manage this risk proactively. In response to immediate threats (including attacks), prey may respond reactively through behavioral countermeasures (Creel 2018). The energetic, reproductive, and opportunity costs that ensue from these adjustments determine the magnitude of any associated risk effects (Creel \& Christianson 2008). Thus, the type of anti-predator behavior exhibited by a prey individual in any situation is crucial to whether and to what extent it will experience fitness penalties. 
Prey individuals that perceive danger may also experience stress, which may affect fitness (Clinchy et al . 2013) and thereby precipitate risk effects either alone or in concert with other (e.g., lost opportunity) costs of anti-predator behaviors. Accordingly, during phase two, factors that influence the strength of responses to perceived risk, the form of anti-predator behaviors, and the amount of associated stress could act as important drivers of contingency in associated predator risk effects experienced directly by prey and ensuing propagation of NCEs.

In phase three, the responses of the forager to intrinsic risk can give rise to indirect effects on other species. Risk effects from predator-induced risk management and stress can reduce prey population size (Creel \& Christianson 2008) and thereby trigger indirect interactions if prey abundance drops enough to affect other community members. Moreover, the nature of prey risk management can determine whether and how other species in the community are affected indirectly. Some behavioral adjustments may only affect the prey species that responds to perceived risk, potentially leading to direct risk effects, whereas others may further (or exclusively) influence third parties and thereby propagate through ecological communities as indirect interactions. Therefore, any factor that modulates the impacts of perceived risk on prey population size and anti-predator behaviors also has the potential to shape indirect NCEs.

\section{Potential drivers of context dependence in NCEs}

\section{Properties of the prey}

Within prey guilds, species employ various means to detect (Weissburget al . 2014), evade (Moore \& Biewener 2015), and resist (Creel 2011) predators. Modes of detection (acoustic, chemical, olfactory, visual, tactile) enable prey to identify risky places, for example by quantifying spatial variation in the intensity of persistent predator cues; and risky times, as when a predator's approach is observed (Creelet al . 2008). Sensory modalities for perceiving and responding to risk are a critical source of contingency during phase one (Fig. 1 ). Prey species may lack the capacity to detect persistent evidence of a predator's presence and thus to prepare for encounters, or instances when predator-prey spatial overlap is such that detection of one by the other is possible (Lima \& Dill 1990). Alternatively, their preparation for encounters may be continuous and generalized, leading to high fitness costs and reduced efficacy (Creel et al . 2008; Creel 2018). Similarly, inability to sense the approach of a predator limits reactive responses to those triggered by an attack (e.g., physical resistance; Creel 2018). In sum, then, consideration of sensory biology should aid in predicting which members of prey guilds are least likely to be subject to non-consumptive (versus consumptive) effects of a predator, and which kinds of risk stimuli (background versus immediate) are most likely to induce defensive responses by a given prey species.

The kinds of sensory modalities used to perceive predation risk should also shape the propagation of NCEs during phases two and three (Fig. 1 ). First, different sensory modalities may mediate the type and intensity of information transferred from a risk cue to prey (Weissburg et al . 2014). Thus, sympatric prey species that use different senses to detect the same predator may respond with divergent intensity and/or specificity depending upon the pathway through which they receive and process the information (Weissburg et al . 2014). The threat level and predator identity perceived by a given prey species could influence its response and any associated risk effects (including from stress) during phase two, as well as any indirect interactions precipitating during phase three. Second, prey with multiple sensory modalities may be better able to detect predators and have an anti-predatory advantage (Munoz \& Blumstein 2012). For example, access to both visual and chemical cues allowed for more accurate detection and appropriate responses to predators by mosquito fish (Gambusia holbrooki) (Ward \& Mehner 2010). Thus, members of prey guilds with multiple sensory modalities may exhibit more striking and appropriate anti-predator responses, higher vulnerability to risk effects, and greater capacity to transmit indirect NCEs to other community members than sympatric heterospecifics relying on a single means of detection.

Although some may double as routine safeguards, tactics for evading and resisting predator attacks are typically reactive countermeasures triggered by encounters with predators (Creel 2018). Thus, these 'escape behaviors' (Heithaus et al . 2009; Wirsing et al . 2010) usually act as drivers of contingency during the 
latter two phases of non-consumptive interactions, after risk is perceived. Evasive behaviors are diverse and include altered activity (Schmitz 2007), body part autotomy (Maginnis 2006), dynamic flash coloration (Murali 2018), feigning death (Humphreys \& Ruxton 2018), fleeing (Moore \& Biewener 2015), grouping (to confuse predators or dilute risk; Lehtonen \& Jaatinen 2016), hiding/crypsis (Caro 2014), and seeking a refuge (Sih 1987). Their efficacy can be prey- and predator-specific and hinge on environmental features (Heithaus et al . 2009; Wirsing et al . 2010; Schmitz 2017; Creel 2018). The effectiveness of flash coloration as a means of visually confusing predators, for example, can depend on visual obstructions, light levels, and background colors (Murali 2018). To the extent that prey have scope to modify the effectiveness of their escape tactics, interspecific variation in evasive behaviors may lead to differences in anti-predator responses to the same risk stimuli during phase two. For example, sympatric prey species that flee predators with disparate means of locomotion may respond divergently to a shared predator by proactively seeking areas that suit their respective movement styles in preparation for an encounter or reactively shifting to these areas after an encounter has occurred. Consistent with this expectation, mule deer (Odocoileus hemionus ) and white-tailed deer (O. virginianus ) exhibited divergent proactive shifts to terrain suiting their respective running gaits (bounding and galloping) when exposed to gray wolves (Canis lupus) (Dellinger et al . 2019; Fig. 2 ). A similar scenario characterizes NCEs of tiger sharks (Galeocerdo cuvier ) on a community of vertebrates in the seagrass ecosystem of Shark Bay, Australia (Heithaus et al . 2012; Fig. 3 ). By implication, during phase three, a predator targeting more than one sympatric prey species could impose multiple indirect effects on other community members (e.g., basal resources for the different prey species) that occur because of prey-specific forms of evasion with divergent consequences for distribution (Wirsing \& Ripple 2011). This possibility has not been tested.

Forms of prey resistance may discourage predators prior to an attack or repel an attacker. Resistance may include cooperative defense (Lehtonen \& Jaatinen 2016), induced chemical defense (Mukherjee \& Heithaus 2013), fighting back (Mukherjee \& Heithaus 2013), and honest (e.g., aposematism, pursuit deterrence; Harvey \& Paxton 1981; Caro 1995) and deceptive signaling (e.g., actions that make an individual seem more difficult to capture such as increases in apparent size, mimicry; Caro 2014). As with evasion, the efficacy of resistance may be predator- and setting-specific (Mukherjee \& Heithaus 2013). Chemical defenses of herbivorous insects, for example, are more effective against vertebrate than invertebrate predators, perhaps because of the latter group's enhanced capacity to develop adaptations to tolerate or overcome prey defenses (Zvereva \& Kozlov 2016). Unlike evasive behaviors, however, resistance usually manifests after the predator detects the prey, and often after an attack has been initiated. Rough-skinned newts (Tarichia granulosa), for instance, show little behavioral response to predators (Murray et al . 2004) save to honestly signal by displaying the bright coloration of their underbelly when accosted by a would-be attacker. Hence, these countermeasures are less likely than evasion to result in either costly risk effects (e.g., diminished condition after prolonged foraging disruption) or in changes to prey activity budgets and distributions during phase two (e.g., displacement) that could indirectly affect other species during phase three. For example, adult moose (Alces alces ), which can fight back effectively against wolves (C. lupus), show little spatial response to wolf presence (Nicholson et al . 2014). Not surprisingly, observed indirect effects of wolves on the plants that moose consume appear to be transmitted primarily by the numerical effects of direct predation rather than NCEs (Post et al . 1999). By implication, prey species relying on resistance should respond differently to predation risk, and to be less likely to be vectors of indirect NCEs, than those depending on evasive behaviors. There are studies supporting the former expectation (e.g., Lingle \& Pellis 2002) but it has not been addressed broadly. The latter expectation remains unexplored.

Within populations, prey state may shape individual responses to predation risk and, consequently, propagation of NCEs (Sih et al . 2015; Schmitz 2017). States can be relatively stable (e.g., sex, behavioral type, and epigenetically or genetically derived morphs) or dynamic (e.g., age/developmental stage, current behavior, disease state, learning, nutritional condition, residual reproductive value, and stress level). An individual's state can influence its risk taking behaviors in any of three ways. First, an individual's capacity to recognize danger may be state-dependent, as when prey acquire the capacity to detect and respond appropriately to cues via development/growth and learning (Kavaliers \& Choleris 2001). For example, large bumblebees 
(Bombus terrestris ) are more sensitive to spider risk while visiting inflorescences, likely (at least in part) because they possess eyes with greater visual acuity than smaller conspecifics (Gaviniet al . 2019). Working with fathead minnows (Pimephales promelas), Ferrari et al . (2006) showed that individuals learned to recognize northern pike (Esox lucius) as predators from a paired exposure to conspecific alarm pheromones and pike odor. Once learned, a minnow's fear response increased with the concentration of pike odor alone. Not surprisingly, therefore, naïve individuals often differ markedly from experienced conspecifics in terms of whether (phase one) and how (phase two) they respond to predation risk (Sih et al . 2010). This form of experience-driven contingency in defensive behaviors could give rise to differences in the extent to which individuals (and populations) with divergent amounts of prior predator conditioning transmit indirect NCEs (phase three).

Second, prey state may affect vulnerability, as when individuals in different growth stages are differentially able to outpace (Diamondet al . 2019) or resist (Schmitz 2017) predators. Thus, against any predator, individuals in less susceptible states should have reduced need to invest in countermeasures and, consequently, respond differently to perceived risk than more vulnerable conspecifics during phase two. For example, Christensen (1996) observed that juvenile roach (Rutilus rutilus ) that were beyond the gape limits of their predators invested less in defense (time spent near the surface and jumping out of the water when at risk) than smaller (ingestible) conspecifics. Similarly, Dannock et al . (2019) found that blue wildebeest (Connochaetes taurinus) eschewed chewing while being vigilant following lion (Panthera leo ) playbacks, presumably because mastication hampers predator detection. Thus, the overall pattern of anti-predator behavior characterizing a prey population during phase two, and the degree to which it transmits indirect NCEs during phase three, could hinge on the distribution of states manifested by its constituents. Indeed, where prey switch ontogenetically from being the prey to being the predator of another species (Ferrariet al . 2010), relative abundance of different developmental stages within a population could mediate the extent to which it experiences and transmits versus initiates NCEs. These hypotheses have yet to be evaluated systematically.

Third, a prey's state may influence its willingness to respond to perceived risk, as when individuals with riskprone behavioral types are less likely to invest in anti-predator behavior (Michalko \& Řežucha 2018) or those with compromised energetic state are more willing to expose themselves to danger to avoid starvation (Clark 1994). The former mechanism is gaining support in the literature (Réale et al . 2007; Mittlebach et al . 2012; Sih et al . 2015; Moranet al . 2017). The latter, known as state-dependent risk taking, has long been recognized and is thoroughly explored in a range of taxa (e.g., Box 1 ). Both have consequences for levels of anti-predator investment and subsequent predation rates experienced by prey during phase two. For example, bold mud crabs (Panopeus sapidus) exhibit lower refuging times relative to shyer conspecifics following exposure to predator cues, and consequently experience higher predation from blue crabs (Callinectes sapidus) (Belgrad \& Griffen 2016). Rainbow trout (Onchorhynchus mykiss) with reduced access to food take greater risks to achieve growth and, consequently, suffered increased predation mortality (Biro et al . 2005). Thus, the extent to which any prey population is subject to consumptive versus non-consumptive predator effects may depend on its average behavioral type (Sih et al . 2004; Moran et al . 2017) or its mean energetic state (Anholt \& Werner 1995; Heithaus et al . 2008; Matassa \& Trussell 2014). These scenarios have only rarely been assessed under large-scale field conditions (e.g., Sinclair \& Arcese 1995). The additional inference that mean temperamental or energetic states should influence the transmission of indirect NCEs in communities has, to our knowledge, not been addressed.

Finally, prey may possess constitutive (permanent) defenses that influence risk-taking behavior including armor, harmful morphology (e.g., spines), toxicity/unpalatability, and honest or deceptive advertisments of similarity to toxic/unpalatable heterospecifics (Tollrian \& Harvell 1999). In theory, the effectiveness of these defenses should be inversely proportional to the need for anti-predator behavior (Dewitt et al . 1999). Freshwater snails (Physa gyrina) with vulnerable shell shapes, for instance, exhibited greater behavioral responses (refuging, avoidance) than harder-to-kill conspecifics when confronted by cues from crayfish (Orconectes rusticus ) (Dewitt et al . 1999). By implication, taxa that are well defended constitutively should exhibit weaker anti-predator responses than other community members with less effective constitutive defen- 
ses during phase two, whether or not cues are detected in phase one, and be less likely to transmit indirect NCEs during phase three. However, the effectiveness of any constitutive defense is, itself, context dependent. For example, Pokallus \& Pauli (2016) observed that, despite possessing a well-developed predator deterrent (quills), porcupines (Erethizon dorsatum ) altered their movements to reduce risk from fishers (Pekania pennanti), a specialized porcupine predator. Hence, even prey with generally effective constitutive protections may react to and transmit indirect NCEs elicited by predators that can, under some circumstances, breach their defenses.

\section{Properties of the predator}

The means by which predators capture their prey, or their hunting modes, are a pervasive driver of context dependence in NCEs (Preisser et al . 2007). Hunting predators, and their prey, are also characterized by a habitat domain, or the spatial extent over which individuals move while foraging (Schmitz 2005; Schmitz et al . 2017a). Together, these properties form the 'hunting mode-habitat domain concept', which aims to explain spatiotemporal contingency in the nature of predator-prey interactions. It can predict how foraging predators and prey should interact during the three phases as a consequence of contingencies in their spatial movement and overlap, the nature of which depends on how prey respond to the threat of predation across space.

Habitat domain size appears to be consistent among predators with similar hunting modes (Miller et al . 2014). At one extreme of a continuum, actively roaming/coursing predators typically have large habitat domains; at the other, sit-and-wait/ambush predators usually exhibit smaller domains. Notably, predators may switch hunting modes (Helfman 1990; Olson \& Eklov 2005; Donihue 2016), which can change space use, habitat domain size, and contingency in the nature of interactions. Smaller prey may forage locally, whereas larger prey may roam widely depending on their forage requirements in relation to the distribution of plant (or other resource) quality and productivity (Haskell et al . 2002), creating contingency in prey movement and habitat domain size. Further contingencies could arise if prey have different habitat domain sizes as they adjust their movement behaviours to the type of predator they face (Fischhoff et al . 2007; Merrillet al . 2010; Miller et al . 2014).

The spatiotemporal nature of predator-prey movement and overlap may determine prey perception of predation risk (phase one). Sit-and-wait predators, by remaining sedentary in fixed locations, create a continuous presence within a narrow habitat domain (Schmitz 2007; Schmitz et al . 2017a). Consequently, prey facing sit-and-wait predators may have a heightened perception of risk because of the persistent point-source cue of predator presence. Actively hunting predators roam widely and thereby often produce diffused, moderate cues in any given location within their broad habitat domain, resulting in lower perception of risk by prey (Schmitz 2007). Consistent with this framework, Murie \& Bourdeau (2019) observed that herbivorous snails (Tegula funebralis ) altered their distribution in an intertidal ecosystem in response to the purple sea star Pisaster ochraceus, which moves slowly within a narrow domain producing an acute and spatially localized acute risk signature. These snails did not alter their distribution when exposed to crab and octopus predators that hunt actively within larger domains and generate diffuse risk profiles. Hence, relative to sedentary predators occupying narrow habitat domains, active predators with large domains may be less likely to initiate direct and indirect NCEs that play out during phases two and three (e.g., Schmitz 2008).

Prey responding to predator cues (phase two) must weigh potentially considerable opportunity costs, in terms of energy and nutrient intake (up to $25 \%$ of daily energy expenditure: Schmitz [2005]) and survival, of remaining continuously vigilant given the likelihood of encountering and being captured by a predator. Thus, prey occupying landscapes with sit-and-wait predators may accept those costs and respond with chronically heightened apprehension. This response could involve heightened vigilance at the expense of reduced foraging, or seeking safety in refuges, or both, depending on the sizes of their habitat domain relative to their predator's (Schmitz 2005). Alternatively, prey facing active hunting predators may encounter predators infrequently. Under these circumstances the prey should not be chronically apprehensive and incur a large energetic penalty. Rather, prey under these conditions should react acutely to imminent risk by simply evading predators upon encounter (Schmitz 2005). There is evidence that these divergent phase two 
scenarios can govern the nature of indirect NCEs in phase three. For example, Schmitz et al . (2017b) found that chronic avoidance of sit-and-wait spider predators by grasshoppers increased plant diversity while decreasing soil carbon retention, whereas a predator guild dominated by actively-hunting spiders failed to elicit grasshopper anti-predator behavior and, consequently, did not indirectly affect plant composition and soil carbon via a non-consumptive pathway.

Whether or not a predator-prey interaction during phase two is largely consumptive or non-consumptive will depend on the relative habitat domain sizes of predators and prey (Schmitz et al . 2004; Schmitz 2005). There are at least four contingencies that can arise, with non-consumptive effects being predominant in three of the four. Whenever prey and predator have overlapping, narrow habitat domains, prey will respond with chronic vigilance. Prey with narrow habitat domains that face widely roaming predators with broad habitat domains will likewise be chronically vigilant. Prey with broad habitat domains should seek refuge by shifting habitat use when facing predators with a narrow habitat domain. Finally, when prey and predators both have broad habitat domains, prey are less prone to exhibit habitat shifts or chronic vigilance, in which case consumptive effects (phase two) and their indirect consequences (phase three) should predominate (Schmitz et al . 2004; 2017a).

Predator state is also a factor that can shape NCEs. State variation can drive differences in a predator's detectability (Scherer \& Smee 2016) and motivation to seek (i.e., its activity and, consequently, spatiotemporal pattern of cue generation) and/or successfully attack (i.e., its lethality) prey (Brown \& Kotler 2004; Brown et al . 2016). This variation can range from being highly dynamic, as when predator hunger elicits increased foraging activity (Hooten et al . 2019), to persistent, as when aggressive behavioral types are more likely to attack prey given an encounter (e.g., Michalko \& Řežucha 2018). During phase one, dynamic changes to a predator's feeding states can change how detectable it is to prey that rely on cues from depredated conspecifics as signals of danger. For instance, mud crabs (Panopeus herbstii) detected and responded to predatory blue crabs (Callinectes sapidus ) that had recently been fed a mud crab diet at a greater distance than food-restricted blue crabs (Weissburg \& Beauvais 2015). By implication, predator populations that rely on such prey species may be more likely to initiate NCEs that cascade through to phase three. In the Weissburg \& Beauvais (2015) study, blue crabs that had fed recently on mud crabs indirectly reduced consumption of a basal resource (oysters) by mud crabs to a greater degree than their hungry counterparts.

During phase two, dynamic predator state changes can influence the strength of anti-predator responses by prey over short intervals (e.g., when hungry predators are perceived as more threatening; Box 1 ). Thus, prevalence of certain states within predator populations (e.g., compromised energetic state) could drive changes to overall prey risk taking that are large enough to affect propagation of indirect NCEs during phase three. More persistent differences in predator state can give rise to marked inter-individual variation in the anti-predator behavior induced by predators during phase two (Sih et al . 2012). For example, Winandy \& Denoël (2015) found that goldfish (Carassius auratus) with aggressive temperaments elicited greater reduction in newt (Lissotriton helveticus ) foraging than less aggressive conspecifics. By implication, the temperamental mix of predator populations could influence the nature of prey defenses during phase two and the likelihood of cascading NCEs in phase three.

\section{Properties of the setting}

Both prey and predator traits crucially predict the outcome of their non-consumptive interactions. Additionally, the propagation of NCEs depends also on the setting in which the interaction takes place. During phase one, changes to the environment may impair prey detection of predator cues by disrupting acoustic (e.g., owing to anthropogenic noise; Chan et al . 2010), chemosensory (e.g., because of pollution; Lürling \& Scheffer 2007), or visual (e.g., via increased turbidity; Abrahams \& Kattenfield 1997) systems. These environmental changes may reduce the likelihood of, or even preclude, anti-predator behavior. For example, predator avoidance by freshwater snails (Physa acuta, Helisoma trivolvis) disappeared when eutrophication of their outdoor mesocosms led to chemosensory impairment (Turner \& Chislock 2010). Environmental features that impede predator detection may themselves be recognized as risk cues by prey and thereby result in elevated defensive investment. For example, Embar et al . (2011) demonstrated that gerbils (Gerbillus 
andersoni allenbyi ) reduced their foraging activity (measured by GUDs) when landscape features blocked sightlines that were necessary for anti-predator vigilance. In general, then, environmental heterogeneity with respect to properties that influence predator detection may mediate substantial inter-individual and population variation in the degree to which prey recognize predation danger and subsequently experience and transmit NCEs.

During phase two, properties of the setting may influence the scope for prey anti-predator behavior in several ways. First, predator and prey habitat domains are shaped in part by environmental context (e.g., thermal conditions, vegetative structure; Schmitz \& Barton 2014). Accordingly, environmental factors constraining prey movement or the amount of predator-free space could dictate whether prey manifest chronic anti-predator vigilance, use refugia, or experience consumptive effects under the four contingent scenarios described above. Barton \& Schmitz (2009) showed, for example, that experimental warming created enemyfree space by shifting the environment from one where two spider predators were spatially complementary to overlapping. This led to a strictly non-consumptive interaction whereby grasshoppers avoided predators rather than a composite scenario where they avoided the sit-and-wait predator but experienced consumptive effects of the active hunter.

Second, even when predator and prey domains are unaffected by the setting, landscape features can shape NCEs by modifying the efficacy of prey escape behavior. The ability of an individual to escape a predator following an encounter can depend on environmental factors that influence mobility (e.g., terrain) or visibility (e.g., when the background affects prey camouflage) (Wirsing et al . 2010). Thus, areas with properties that render prey escape tactic(s) less effective are likely to be avoided, at least when predators are present, or to elicit other countermeasures that enhance the probability of early predator detection (e.g., vigilance). For instance, reef habitat complexity enhanced and dampened anti-predator behaviors of large and small fishes, respectively, likely because large-bodied fish are less able to flee from predators through obstacle-rich reefscapes than their smaller counterparts (Catano et al . 2016).

Third, food quantity or quality at the landscape scale can shape NCEs by influencing the mean energetic state of prey populations (Heithauset al . 2008; Wirsing \& Ripple 2011). In depauperate landscapes, average energetic states will be depressed and the overwhelming necessity of food should drive foraging decisions (Chesson \& Kuang 2008), whereas anti-predator investments should increase when resources are plentiful and prey have nutritional reserves (Hopcraft et al . 2010; Matassa \& Trussell 2014). For example, Matassa et al . (2016) found that elevated resource (barnacle, Semibalanus balanoides ) density strengthened antipredator investment (refuge use) by sub-adult snails (Nucella lapillus ) exposed to risk cues from predatory crabs (Carcinus maenas), presumably by augmenting prey state.

Fourth, interacting predator-prey pairs are unlikely to do so in isolation from other species, which may alter the focal prey species' responses to perceived risk. For instance, dwarf mongooses (Helogale parvula ) displayed lower rates of anti-predator vigilance when in the presence of an avian co-forager, the drongo (Dicrurus adsimilis ) (Sharpe et al . 2010). The presence of other predators may also affect the transmission of NCEs if prey species with conflicting predator-specific responses consequently reduce their investment in defense (Sih et al . 1998). In accord with predator facilitation (Charnov et al . 1976; Kotler et al . 1992; Korpimaki et al . 1996), for example, Meadows et al . (2017) showed that larval mosquitoes (Culex pipiens ) abandoned diving behavior normally deployed to escape surface-hunting insect mesopredators when also exposed to a benthic predator (dragonfly naiads,Aeshna spp.).

Lastly, landscape properties may mediate how prey are affected by temporal variation in predation risk (Box 2 ). Many nocturnal animals, for example, decrease their activity on moonlit nights because of their increased exposure to visually-orienting predators, and this trend is accentuated in areas dominated by open habitats (Prugh \& Golden 2014). Therefore, moonlight exacerbation of NCEs experienced by nocturnal prey species is likely to be inversely proportional to landscape cover availability. Landscapes also may influence temporal patterns of predation risk, and thus NCEs, over longer intervals. Seasonal variation in snow accumulation, for example, can give prey a temporary refuge or heighten vulnerability to predation by restricting mobility (Gorini et al . 2011). Not surprisingly, snow depth has been linked to prey risk taking (e.g., yarding in deer; 
Nelson \& Mech 1991).

Any of these environmental attributes, alone or in concert, can influence the kinds of anti-predator behaviors that manifest during phase two and that precipitate as indirect NCEs during phase three (Heithaus et al . 2009; Wirsing \& Ripple 2011). Thus, direct and indirect non-consumptive relationships between the same suites of interacting predator and prey species may differ markedly as a function of landscape type. Trussell et al . (2006) determined, for example, that habitat type (availability of refugia) shaped how risk from crabs (Carcinus maenas) altered the foraging intensity of a snail (Nucella lapillus) and, consequently, the levels of consumption of the snails' resource (S. balanoides ).

\section{The magnitude of contingency}

To quantify strength of contingency in NCEs, we conducted a meta-analysis of the relationship between four types of prey risk taking and a key hypothesized driver of context dependence: prey energetic state (Kotler et al . 2004; Schmitz \& Trussell 2016; seeBox 3 for methods). Reduced energetic state resulted in significantly elevated prey risk taking in each behavioral dimension (Fig. 4 ). When in a compromised energetic state, prey subjected to predation risk tended to be more active $(d=0.73, \pm 95 \% \mathrm{CI}=0.32-1.14$; $\operatorname{lnRR}=0.34, \pm 95 \% \mathrm{CI}=0.17-0.51)$, spend less time in refugia $(d=0.95, \pm 95 \% \mathrm{CI}=0.74-1.16 ; \operatorname{lnRR}=$ $0.58, \pm 95 \% \mathrm{CI}=0.46-0.71)$, invest more in foraging versus apprehension $(d=0.84, \pm 95 \% \mathrm{CI}=0.50-1.19$; $\operatorname{lnRR}=0.49, \pm 95 \% \mathrm{CI}=0.22-0.77)$, and be more isolated from other group members $(d=0.86, \pm 95 \%$ $\mathrm{CI}=0.29-1.42 ; \operatorname{lnRR}=0.42, \pm 95 \% \mathrm{CI}=0.19-0.65)$ than conspecifics in better nutritional condition. The mean estimates of $d$ suggest a medium/strong effect of reduced energetic state on prey activity, and strong effects on exposure, foraging investment, and isolation. We detected significant heterogeneity among studies exploring each risk-taking dimension: activity $\left(d: Q_{33}=178.39, \mathrm{p}<0.001 ; \operatorname{lnRR}: Q_{33}=88.04, \mathrm{p}<0.001\right)$; exposure $\left(d: Q_{70}=213.60, \mathrm{p}<0.001 ; \operatorname{lnRR}: Q_{70}=369.66, \mathrm{p}<0.001\right)$; foraging investment $\left(d: Q_{40}=\right.$ 186.19, $\mathrm{p}<0.001$; $\left.\operatorname{lnRR}: Q_{40}=924.42, \mathrm{p}<0.001\right)$; isolation $\left(\left(d: Q_{9}=34.85, \mathrm{p}<0.001 ; \operatorname{lnRR}: Q_{9}=\right.\right.$ 57.06, $\mathrm{p}<0.001)$.

These results underscore the marked differences that can characterize risk taking by prey individuals with divergent energetic states, and by extension the pivotal role that prey condition plays as a mediator of direct NCEs in communities. Most of the studies included in this analysis examined small-bodied taxa in laboratory or small-scale mesocosm settings (Appendix S1 in Supporting Information), and we found few investigations of the indirect community consequences of state-mediated variation in prey risk taking. Accordingly, there remains need for studies quantifying the influence of energetic state on risk taking under field conditions, especially with larger-bodied species, and the degree to which disparate responses of prey in divergent nutritional states shape indirect predator NCEs. Furthermore, prey state was the only potential driver of contingency in prey anti-predator behavior subject to enough empirical investigation to support meta-analysis. Thus, we also encourage further work addressing other potential drivers of context dependent NCEs.

Our findings also revealed considerable variability in the magnitude and direction of the effect of prey condition on anti-predator behavior. Some studies in each of the four behavioral categories showed effects opposite the majority of studies. In these studies, anti-predator behavior increased with decreasing body condition or state of the prey ( 7 of 34 studies of activity; 7 of 71 for exposure; 5 of 41 for foraging investment; 1 of 10 for isolation). This variability may, in part, stem from the myriad means by, and circumstances under, which the experiments of the meta-analyses were conducted. The variability in results is also consistent with the idea that, during phase two, anti-predator behavior and the way it is shaped by context (including prey state) hinge on the relative safety benefits conferred by different behavioral options available to the prey species. Either increased or decreased activity, for example, can serve as effective anti-predator tactics depending on the hunting mode of the predator against which they are deployed (Schmitz 2007). Furthermore, if individuals in a low state are more vulnerable to predation, then they may adopt a higher level of antipredator investment (Raveh et al . 2011; Makon et al .in press ). It is not surprising, then, that some studies we assessed found that sated prey exposed to predation risk became more active, and that food restriction diminished rather than exacerbated this response (e.g., Hossie \& Murray 2011). Though beyond the scope 
of this review, meta-regressions with covariates potentially influencing the efficacy of different anti-predator behaviors (e.g., predator type) would likely reduce some of the uncertainty characterizing our findings.

\section{Conclusions and future directions}

In a recent review of context-dependent species relationships, Chamberlain et al . (2014) called for increased scrutiny of the factors contributing to, and the ecological and evolutionary consequences of, variation in interaction outcomes. Focusing on non-consumptive predator-prey interactions, we address both of these knowledge gaps. First, we present new insights into NCEs by showing when and how contingency can arise from properties of the prey, the predator, and the setting as these effects unfold across three phases (prey risk perception; prey responses to perceived risk; impacts of these responses on other species). Second, while recognizing that there is more work to be done, we help to unravel the consequences of contingency by quantifying the extent to which prey energetic state drives differences in anti-predator behavior, and by spotlighting cases where variation in the outcome of non-consumptive predator-prey interaction has shaped the indirect NCEs experienced by other community members. Our synthesis also highlights two knowledge deficiencies - insufficient exploration of context-dependent indirect NCEs during phase three and the ways in which direct and indirect NCEs are shaped simultaneously, or even interactively, by multiple drivers of context dependence - that must be remedied if we are to develop a coherent framework for predicting NCEs.

Drawing from a broad literature spanning diverse taxa and ecosystems, our review reveals how contingencies in NCEs can arise as a result of many factors. It is hardly surprising, then, that studies have revealed so much variation with respect to whether, and in what way, NCEs manifest in communities (Moll et al . 2016; Schmitz 2017; Gaynoret al . 2019; Prugh et al . 2019). We clarify these factors by grouping them into three broad categories: (1) prey properties that influence detection of and responses to risk; (2) predator properties shaping their detectability and lethality; and (3) properties of the setting that influence the prey's scope for predator detection and countermeasures. We also emphasize that there is great potential for interplay among them. For example, divergent responses to predators with disparate hunting modes could disappear if declining food supply limits prey capacity for defensive investment. Similarly, because prey often have multiple defenses whose efficacies are context-specific (Brittonet al . 2007; Wirsing et al . 2010; Wirsing \& Ripple 2011; Schmitz 2017; Creel 2018), sympatric prey may respond divergently to a shared predator in one setting but similarly in another, depending on the availability of landscape features that facilitate particular responses (e.g., refuge space). Moreover, the latter two give rise to an emergent fourth driver, (4) the timing of predation risk, and prey properties then determine how individuals respond to this temporal dimension of danger (Box 2 ). By implication, predictions based on a single driver of contingency may provide an incomplete picture of the impacts of predation risk on prey populations and communities. Rather, examination of NCEs requires thorough consideration of the functional properties of interacting predator and prey species, as well as the circumstances under which these interactions occur (Heithauset al . 2009; Wirsing et al . 2010; Creel 2011; Schmitz 2017). Fortunately, many of these natural history or environmental details are available or attainable (Wirsing et al . 2010), especially given new approaches (e.g., animal-borne video, camera traps, drones) that facilitate placing behavioral data in context (Mollet al . 2007; Wirsing \& Heithaus 2014).

Our review also highlights the staged manner in which NCE contingencies can manifest. Namely, prey antipredator investment may vary intra- and inter-specifically as a function of differences in sensory perception (phase one) and the form of any deployed countermeasures (phase two); contingent outcomes during either of the first two phases then determine if, and in what way, indirect NCEs emerge during phase three. Identifying the phase(s) in which context dependence arises is therefore crucial to predicting how the outcome of nonconsumptive predator-prey interactions will respond to perturbation. For example, landscape changes that constrain prey habitat domains and raise the frequency of encounters with predators may elicit increased anti-predator defense during phase two (Schmitz et al . 2004; 2017a) and thereby elevate the potential for indirect NCEs in phase three. However, such changes would be expected to have minimal non-consumptive impact on prey species lacking the ability to detect risk cues during phase one, unless they also reshape the sensory environment. Thus, studies exploring the phase-specific mechanisms by which prey, predator, 
and landscape properties shape anti-predator investment will strengthen a general framework for forecasting NCEs in a changing world.

Recent syntheses have quantified the degree to which NCEs vary as a function of resource competition (Bolnick \& Preisser 2005), predator hunting mode and habitat domain (Preisser et al . 2007), resource dynamics (Preisser et al . 2009), and refuge availability (Orrocket al . 2013). The results of our meta-analysis add prey energetic state to the growing list of drivers whose strong impact on the outcomes of NCEs has been quantified across systems and taxa. Notably, our findings differ somewhat from those listed above because we addressed multiple forms of antipredator behavior and only chose experiments explicitly contrasting responses of prey individuals with different energetic states to risk. Hence, we offer novel insights into the manifold ways in which energetic state can shape patterns of anti-predator investment under conditions where the potentially confounding effects of differing environments and other prey traits have been minimized. Our findings also highlight the varied ways by which state-dependent variation in anti-predator behaviors might influence the manifestation of indirect NCEs during phase three - for example via differences in vigilance or space use - though these hypothetical scenarios remain to be evaluated empirically.

Our survey revealed two knowledge gaps that represent fruitful directions for future research. First, whereas there is ample evidence for context dependence during phases one and two, few studies have rigorously examined contingency in the propagation of indirect NCEs. There are notable examples, including the role of predator hunting mode in shaping indirect NCEs of spiders on plant and soil properties (Schmitz et al . $2017 \mathrm{~b}$ ), and the impact of the presence or absence of prey refugia on indirect non-consumptive relationships between crabs and barnacles (Trussell et al . 2006). These studies offer a template for expanded scrutiny of contingencies in NCEs during phase three, which will improve our understanding of when and how predators initiate indirect effects by altering prey traits.

Second, a growing literature underscores the importance of simultaneously considering multiple drivers of contingency in NCEs. For example, anti-predator investment by mud crabs varied with their personality (bold versus shy) and predator hunting mode (actively hunting blue crabs versus sit-and-wait toadfish, Opsanus tau ) (Belgrad \& Griffen 2016). Working in a large vertebrate system, Thakeret al . (2011) showed that small members of an African ungulate guild avoided all predators whereas their larger counterparts avoided sit-and-pursue but not active hunters. More work is needed, however, particularly on the importance of three-way interactions among factors drawn from the aforementioned groups.

There are also studies suggesting that interactive impacts of multiple contingent drivers may act collectively to shape indirect NCEs during phase three. For example, Murie \& Bourdeau (2019) speculated that, compared to the strong effects initiated by slow-moving sea stars, the absence of direct and indirect non-consumptive effects of crabs and octopuses on snail grazing and kelp, respectively, might owe to the inability of snails to escape these vagile predators. By inference, more mobile prey species with greater scope for avoidance may have responded equivalently to all three predators, yielding similar rather than predator-specific cascades of NCEs. The possibility that interactions between context dependent factors might modify cascading NCEs has yet to be tested empirically, however, and thus remains as an exciting research frontier.

\section{Acknowledgements}

This review was made possible by NSF DEB grants 1145902 (to A. Wirsing) and 1145522 (to M. Heithaus). We are grateful to L. Prugh for statistical advice. This is publication xx of the Mitrani Department of Desert Ecology, xx of the Shark Bay Research Project, and xx of the Coastlines and Oceans Division of FIU's Institute of Environment.

\section{Literature Cited}

Abrahams, M.V. \& Kattenfield, M.G. (1997). The role of turbidity as a constraint on predator-

prey interactions in aquatic environments. Behav. Ecol. Sociobiol ., 40, 169-174.

Anholt, B.R. \& Werner, E.E. (1995). Interaction between food availability and predation 
mortality mediated by adaptive behavior. Ecology , 76, 2230-2234.

Barton, B.T. \& Schmitz, O.J. (2009). Experimental warming transforms multiple predator effects in a grassland food web. Ecol. Lett ., 12, 1317-1325.

Basille, M., Fortin, D., Dussault, C., Bastille-Rousseau, G., Ouellet, J. \& Courtois, R. (2015).

Plastic response of fearful prey to the spatiotemporal dynamics of predator distribution. Ecology, 96, 26222631.

Begg, C. \& Mazumdar, M. (1994). Operating characteristics of a rank correlation test for publication bias. Biometrics , 50, 1088-1101.

Belgrad, B.A. \& Griffen, B.D. (2016). Predator-prey interactions mediated by prey personality and predator hunting mode. Proc. R. Soc. B ., 283, 20160408.

Berger-Tal, O. \& Kotler, B.P. (2010). State of emergency: behavior of gerbils is affected by the hunger state of their predators. Ecology , 91, 593-600.

Berger-Tal, O., Mukherjee, S., Kotler, B.P. \& Brown, J.S. (2010). Complex state-dependent games between owls and gerbils. Ecol. Lett ., 13, 302-310.

Bessey, C., Heithaus, M.R., Fourqurean, J.W., Gastrich, K.R. \& Burkholder, D.A. (2016).

Importance of teleost macrograzers to seagrass composition in a subtropical ecosystem with abundant populations of megagrazers and predators. Mar. Ecol. Prog. Ser., 553, 81-92.

Biro, P.A., Post, J.R. \& Abrahams, M.V. (2005). Ontogeny of energy allocation reveals selective pressure promoting risk-taking behaviour in young fish cohorts.Proc. R. Soc. B., 272, 1443-1448.

Bolnick, D.I. \& Preisser, E.L. (2005). Resource competition modifies the strength of traitmediated predator-prey interactions: a meta-analysis. Ecology , 86, 2771-2779.

Britton, N.F., Planqué, R. \& Franks, N.R. (2007). Evolution of defense portfolios in exploitervictim systems. Bull. Math. Biol. , 69, 957-988.

Brown, J.S. (1999). Vigilance, patch use and habitat selection: foraging under predation risk. Evol. Ecol. Res ., 1, 49-71.

Brown, J.S. (1988). Patch use as an indicator of habitat preference, predation risk, and competition. Behav. Ecol. Sociobiol ., 22, 37-47.

Brown, J.S. \& Kotler, B.P. (2004). Hazardous duty pay and the foraging cost of predation. Ecol. Lett ., 7, 999-1014.

Brown, J.S., Embar, K., Hancock, E. \& Kotler, B.P. (2016). Predators risk injury too: the evolution of derring-do in a predator-prey foraging game. Isr. J. Ecol. Evol ., 62, 196-

204.

Burkholder, D.A., Heithaus, M.R., Fourqurean, J.W., Wirsing, A. \& Dill, L.M. (2013). Patterns of top-down control in a seagrass ecosystem: could a roving predator induce a behaviour-mediated trophic cascade? J. Anim. Ecol., 82, 1192-1202. 
Caro, T. (2014). Antipredator deception in terrestrial vertebrates. Curr. Zool. , 60, 16-25.

Caro, T.M. (1995). Pursuit-deterrence revisited. Trends. Ecol. Evol. , 10, 500-503.

Catano, L.B., Rojas, M.C., Malossi, R.J., Peters, J.R., Heithaus, M.R., Fourqurean, J.W. et al.

(2016). Reefscapes of fear: predation risk and reef hetero-geneity interact to shape herbivore foraging behaviour. J. Anim. Ecol., 85, 146-156.

Chamberlain, S.A., Bronstein, J.L. \& Rudgers, J.A. (2014). How context dependent are species interactions? Ecol. Lett ., 17, 881-890.

Chan, A.A.Y., Giraldo-Perez, P., Smith, S. \& Blumstein, D.T. (2010). Anthropogenic noise affects risk assessment and attention: the distracted prey hypothesis.Biol. Lett., 6, 458-461.

Charnov, E.L., Orians, G.H. \& Hyatt, K. (1976). Ecological implications of resource depression. Am. Nat ., 110, 247-259.

Chesson, P. \& Kuang, J.J. (2008). The interaction between predation and competition. Nature, 456, 235-238.

Christensen, B. (1996). Predator foraging capabilities and prey antipredator behaviours: preversus postcapture constraints on size-dependent predator-prey interactions. Oikos, 76, 368-380.

Clark, C.W. (1994). Anti-predator behavior and the asset protection principle. Behav. Ecol ., 5, $159-170$.

Clinchy, M., Sheriff, M.J. \& Zanette, L.Y. (2013) Predator-induced and the ecology of fear.

Funct. Ecol. , 27, 56-65.

Courbin, N., Loveridge, A.J., Fritz, H., MacDonald, D.W., Patin, R., Valeix, M. et al . (2019).

Zebra diel migrations reduce encounter risk with lions at night. J. Anim. Ecol., 88, 92-101.

Creel, S. (2018). The control of risk hypothesis: reactive vs. proactive antipredator responses and stress-mediated vs. food-mediated costs of response. Ecol. Lett.21, 947-956.

Creel, S. (2011). Toward a predictive theory of risk effects: hypotheses for prey attributes and compensatory mortality. Ecology , 92, 2190-2195.

Creel, S. \& Christianson, D. (2008). Relationships between direct predation and risk effects. Trends Ecol. Evol ., 23, 194-201.

Creel, S., Winnie Jr., J.A., Christianson, D. \& Liley, S. (2008). Time and space in general models of antipredator response: tests with wolves and elk. Anim. Behav ., 76, 1139-1146. Cresswell, W. (2008). Non-lethal effects of predation in birds.Ibis , 150, 3-17.

Dannock, R.J., Pays, O., Renaud, P.-C., Maron, M. \& Goldizen, A.W. (2019). Assessing blue wildebeests' vigilance, grouping and foraging responses to perceived predation risk using playback experiments. Behav. Process., 164, 252-259.

Darwin C. (1839). Journal of researches into the geology and natural history of the various 
countries visited by H. M. S. Beagle, under the command of captain Fitzroy, R. N. from 1832-1836. Henry Colburn, London, UK.

Dellinger, J.A., Shores, C.R., Craig, A., Heithaus, M.R., Ripple, W.J. \& Wirsing, A.J. (2019).

Habitat use of sympatric prey suggests divergent anti-predator responses to recolonizing gray wolves. Oecologia, 189, 487-500.

Dewitt, T.J., Sih. A. \& Hucko, J.A. (1999). Trait compensation and cospecialization in a freshwater snail: size, shape and antipredator behaviour. Anim. Behav ., 58, 397-407.

Diamond, K.M., Lagarde, R., Schoenfuss, H.L., Walker, J.A., Ponton, D. \& Blob, R.W. (2019).

Relationship of escape performance with predator regime and ontogeny in fishes. Biol. J. Linnean Soc., 127, $324-336$.

Dill, L.M., Heithaus, M.R. \& Walters, C.J. (2003). Behaviorally mediated indirect interactions in marine xommunities and theur conservation implications. Ecology, 84, 1151-1157.

Donihue, C.M. (2016). Aegean wall lizards switch foraging modes, diet, and morphology in a human-built environment. Ecol. Evol., 6, 7433-7442.

Dröge, E., Creel, S., Becker, M.S. \& M'soka, J. (2018). Risky times and risky places interact to affect prey behavior. Nat. Ecol. Evol ., 1, 1123-1128.

Embar, K., Raveh, A., Burns, D. \& Kotler, B.P. (2014a). To dare or not to dare? Risk management by owls in a predator-prey foraging game. Oecologia , 175, 825-834.

Embar, K., Mukherjee, S. \& Kotler, B.P. (2014b). What do predators really want? The role of gerbil energetic state in determining prey choice by barn owls.Ecology , 95, 280-285.

Embar, K., Kotler, B.P. \& Mukherjee, S. (2011). Risk management in optimal foragers: the effect of sightlines and predator type on patch use, time allocation, and vigilance in gerbils. Oikos, 120, $1657-1666$.

Ferrari, M.C.O., Wisenden, B.D. \& Chivers, D.P. (2010). Chemical ecology of predator-prey interactions in aquatic ecosystems: a review and prospectus. Can. J. Zool ., 88, 698-724.

Ferrari, M.C.O., Sih, A. \& Chivers, D.P. (2009). The paradox of risk allocation: a review and prospectus. Anim. Behav ., 78, 579-585.

Ferrari, M.C.O., Capitania-Kwok, T. \& Chivers, D.P. (2006). The role of learning in the acquisition of threat-sensitive responses to predator odours.Behav. Ecol. Sociobiol., 60, 522-527.

Fischhoff, I.R., Sundaresan, S.R., Cordingley, J. \& Rubenstein, D.I. (2007). Habitat use and movements of plains zebra (Equus burchelli) in response to predation danger from lions. Behav. Ecol., 18, $725-729$.

Ford, A.T. \& Goheen, J.R. (2015). Trophic cascades by large carnivores: A case for strong inference and mechanism. Trends Ecol. Evol. , 30, 725-735.

Gavini, S.S., Quintero, C. \& Tadey, M. (2019). Intraspecific variation in body size of bumblebee workers influences anti-predator behavior. J. Anim. Ecol ., in press (accepted). 
Gaynor, K.M., Brown, J.S., Middleton, A.M., Power, M.E. \& Brashares, J.S. (2019). Landscapes

of fear: spatial patterns of risk perception and response. Trends Ecol. Evol ., 34, 355-368.

Gorini, L., Linnell, J.D.C., May, R., Panzacchi, M., Boitani, L., Odden, M. et al. (2011). Habitat

heterogeneity and mammalian predator-prey interactions. Mammal Rev. , 42, 55-77.

Gurevitch, J. \& Hedges, L. (1999). Statistical issues in ecological meta-analyses. Ecology,

$80,1142-1149$.

Gurevitch J. \& Hedges, L.V. (1993). Meta-analysis: Combining the results of independent

experiments. In Design and analysis of ecological experiments(eds Scheiner, S.M., Gurevitch, J.). Chapman and Hall, New York, New York, USA, pp 378-398.

Harvey, P.H. \& Paxton, R.J. (1981). The evolution of aposematic coloration. Oikos , 37, 391-

393.

Haskell, J.P., Ritchie, M.E. \& Olff, H. (2002). Fractal geomery predicts varying body size scaling relationships for mammal and bird home ranges. Nature, 418, 527-530.

Hedges, L.V. \& Olkin, I. (1985). Statistical techniques for meta-analysis . Academic Press, New York, New York, USA.

Hedges, L.V., Gurevitch, J. \& Curtis, P.S. (1999). The meta-analysis of response ratios in experimental ecology. Ecology, 80, 1150-1156.

Heithaus, M.R. \& Dill, L.M. (2006). Does tiger shark predation risk influence habitat use by bottlenose dolphins at multiple spatial scales? Oikos , 114, 257-264.

Heithaus, M.R., Wirsing, A.J. \& Dill, L.M. (2012). The ecological importance of intact toppredator populations: a synthesis of 15 years of research in a seagrass ecosystem. Mar. Freshwater Res., 63, 1039-1050.

Heithaus, M.R., Wirsing, A.J., Burkholder, D., Thomson, J. \& Dill, L.M. (2009). Towards a predictive framework for predator risk effects: the interaction of landscape features and prey escape behavior. J. Anim. Ecol., 78, 556-562.

Heithaus, M.R., Frid, A., Wirsing, A.J., \& Worm, B. (2008). Predicting ecological consequences of marine top predator declines. Trend. Ecol. Evol. , 23, 202-210.

Heithaus, M.R., Frid, A., Wirsing, A.J., Dill, L.M., Fourqurean, J.W., Burkholder, D. et al .

(2007). State-dependent risk-taking by green sea turtles mediates top-down effects of shark intimidation in a marine ecosystem. J. Anim. Ecol., 76, 837-844.

Heithaus, M.R., Hamilton, I.M., Wirsing, A.J. \& Dill. L.M. (2006). Validation of a

randomization procedure to assess animal habitat preferences: microhabitat use of tiger sharks in a seagrass ecosystem. J. Anim. Ecol., 75, 666-676.

Heithaus, M.R., Dill. L.M., Marshall, G.J. \& Buhleier, B. (2002). Habitat use and foraging behavior of tiger sharks (Galeocerdo cuvier) in a seagrass ecosystem. Mar. Biol., 140, 237-248.

Helfman, G. (1990). Mode selection and mode switching in foraging animals. Adv. Stud. Behav ., 
19, 249-298.

Hooten, M.B., Scharf, H.R. \& Morales, J.M. (2019). Running on empty: recharge dynamics from animal movement data. Ecol. Lett ., 22, 377-389.

Hopcraft, J.G., Olff, H. \& Sinclair, A.R.E. (2010). Herbivores, resources, and risks: alternating regulation along primary along environmental gradients in savannas. Trends Ecol. Evol., 25, 119-128.

Hossie, T.J. \& Murray, D.L. (2011). Effects of structural refuge and density on foraging behaviour and mortality of hungry tadpoles subject to predation risk.Ethology, 117, 777-785. Humphreys, R.K. \& Ruxton G.D. (2018). A review of thanatosis (death feigning) as an antipredator strategy. Behav. Ecol. Sociobiol., 72, 22.

Kavaliers, M. \& Choleris, E. (2001). Antipredator responses and defensive behavior: ecological and ethological approaches for the neurosciences. Neurosci. Biobehav. Rev., 25, 577-586.

Kohl, M.T., Stahler, D.R., Metz, M.C., Forester, J.D., Kauffman, M.J., Varley, N. et al . (2018). Diel predator activity drives a dynamic landscape of fear. Ecol. Monogr ., 88, 638-652.

Korpimaki, E., Koivunen, V. \& Hakkarainen, H. (1996). Microhabitat use and behavior of voles under weasel and raptor predation risk: predator facilitation?Behav. Ecol., 7, 30-34.

Kotler, B.P. (1997). Patch use by gerbils in a risky environment: manipulating food and safety to test four models. Oikos , 78, 274-282.

Kotler, B.P. (1984). Risk of predation and the structure of desert rodent communities. Ecology , 65, 689-701.

Kotler, B.P., \& Holt, R.D. (1989). Predation and competition: the interaction of two types of species interactions. Oikos , 54, 256-259.

Kotler, B.P., Brown, J.S., Mukherjee, S., Berger-Tal, O. \& Bouskila, A. (2010). Moonlight avoidance in gerbils reveals a sophisticated interplay among time allocation, vigilance and state-dependent foraging. Proc. R. Soc. B., 277, 1469-1474.

Kotler, B.P., Brown, J.S. \& Bouskila, A. (2004). Apprehension and time allocation in gerbils: the effects of predatory risk and energetic state. Ecology , 85, 917-922.

Kotler, B.P., Brown, J.S., Dall, S.R.X., Gresser, S., Ganey, D. \& Bouskila, A. (2002). Foraging games between gerbils and their predators: temporal dynamics of resource depletion and apprehension in gerbils. Evol. Ecol. Res., 4, 495-518.

Kotler, B.P., Brown, J.S. \& Mitchell, W.A. (1993). Environmental factors affecting patch use in two gerbilline rodents. J. Mammal., 74, 614-620.

Kotler, B.P., Blaustein, L. \& Brown, J.S. (1992). Predator facilitation: the combined effect of snakes and owls on the foraging behavior of gerbils. Ann. Zool. Fenn. , 29, 199-206.

Kotler, B.P., Brown, J.S. \& Hasson, O. (1991). Factors affecting gerbil foraging behavior and rates of owl predation. Ecology, 72, 2249-2260. 
Lank, D.B. \& Ydenberg, R.C. (2003). Death and danger at migratory stopovers: problems with "predation risk". J. Avian Biol., 34, 225-228.

Le Roux, E., Kerley, G.I.H. \& Cromsigt, J.P.G.M. (2018). Megaherbivores modify trophic cascades triggered by fear of predation in an African savanna ecosystem.Curr. Biol., 28, 2493-2499.

Lehtonen, J. \& Jaatinen, K. (2016). Safety in numbers: the dilution effect and other drivers of group life in the face of danger. Behav. Ecol. Sociobiol ., 70, 449-458.

Lima, S.L. (1998). Stress and decision making under the risk of predation: recent developments from behavioral, reproductive, and ecological perspectives. Adv. Study Behav., 27, 215-290.

Lima, S.L. (1992). Strong preference for apparently dangerous habitats - a consequence of differential escape from predators. Oikos , 64, 597-600.

Lima, S.L. \& Bednekoff, P.A. (1999). Temporal variation in danger drives antipredator behavior: the predation risk allocation hypothesis. Am. Nat ., 153, 649-659.

Lima, S.L. \& Dill, L.M. (1990). Behavioral decisions made under the risk of predation: a review and prospectus. Can. J. Zool ., 68, 619-640.

Lingle, S. (1993). Escape gaits of white-tailed deer, mule deer, and their hybrids: body configuration, biomechanics, and function. Can. J. Zool ., 71, 708-724.

Lingle, S. \& Pellis, S. (2002). Fight or flight? Antipredator behavior and the escalation of coyote encounters with deer. Oecologia , 131, 154-164.

Lurling, M. \& Scheffer, M. (2007). Info-disruption: pollution and the transfer of chemical information between organisms. Trends Ecol. Evol ., 22, 374-379.

Maginnis, T.L. (2006). The costs of autotomy and regeneration in animals: a review and framework for future research. Behav. Ecol. , 17, 857-872.

Makon, D. F., Kotler, B.P., Brown, J.S., Garrido, M. \& Menezes, J.F.S. (in press ). Living with the enemy: how an endoparasitic bacterium inhibits the foraging aptitudes and risk management behaviour of Allenby's gerbils. Am. Nat.

Matassa, C.M. \& Trussell, G.C. (2014). Prey state shapes the effects of temporal variation in predation risk. Proc. R. Soc. B , 281, 20141952.

Matassa, C.M., Donelan, S.C., Luttbeg, B. \& Trussell, G.C. (2016) Resource levels and prey state influence antipredator behavior and the strength of nonconsumptive predator effects. Oikos, 125, 14781488 .

Meadows, A.J., Owen, J.P. \& Snyder, W.E. (2017). Keystone nonconsumptive effects within a diverse predator community. Ecol. Evol., 7, 10315-10325.

Merrill, E., Sand, H., Zimmermann, B., McPhee, H., Webb, N., Hebblewhite, M. et al . (2010).

Building a mechanistic understanding of predation with GPS-based movement data. Phil. Trans. R. Soc. B, $365,2279-2288$.

Michalko, R. \& Řezucha, R. (2018). Top predator's aggressiveness and mesopredator's risk- 
aversion additively determine probability of predation. Behav. Ecol. Sociobiol ., 72, 105. Middleton, A.D., Kauffman, M.J., McWhirter, D.E., Jimenez, M.D., Cook, R.C., Cook, J.G. et al . (2013). Linking anti-predator behavior to prey demography reveals limited risk effects of an actively hunting large carnivore. Ecol. Lett., 16, 1023-1030.

Miller, J.R., Ament, J.M. \& Schmitz, O.J. (2014). Fear on the move: predator hunting mode predicts variation in prey mortality and plasticity in prey spatial response. J. Anim. Ecol., 83, 214-222.

Mittlebach, G.G., Ballew, N.G. \& Kjelvik, M. K. (2012). Fish behavioral types and their ecological consequences. Can. J. Fish. Aquat. Sci. , 71, 927-944.

Moll, R.J., Redilla, K.M., Mudumba, T., Muneza, A.B., Gray, S.M., Abade, L. et al . (2017). The many faces of fear: a synthesis of the methodological variation in characterizing predation risk. J. Anim. Ecol., 86, 749-765.

Moll, R.J., Killion, A.K., Montgomery, R.A., Tembling, C.J. \& Hayward, M.W. (2016). Spatial patterns of African ungulate aggregation reveal complex but limited risk effects from reintroduced carnivores. Ecology, 97, 1123-1134.

Moll, R.J., Millspaugh, J.J., Beringer, J., Sartwell, J. \& He, Z. (2007). A new 'view' of ecology and conservation through animal-borne video systems. Trend. Ecol. Evol ., 22, 660-668.

Moore, T.Y. \& Biewener, A.A. (2015). Outrun or outmaneuver: predator-prey interactions as a model system for integrating biomechanical studies in a broader ecological and evolutionary context. Integr. Comp. Biol., 55, 1188-1197.

Moran, N.P., Wong, B.B.M. \& Thompson, R.M. (2017). Weaving animal temperament into food webs: implications for biodiversity. Oikos , 126, 917-930.

Mukherjee, S. \& Heithaus, M.R. (2013). Dangerous prey and daring predators: a review. Biol. Rev ., 88, 550-563.

Munoz, N.E. \& Blumstein, D.T. (2012). Multisensory perception in uncertain environments.

Behav. Ecol. , 23, 457-462.

Murali, G. (2018). Now you see me, now you don't: dynamic flash coloration as an antipredator strategy in motion. Anim. Behav. , 142, 207-220.

Murie, K.A. \& Bourdeau, P.E. (2019). Predator identity dominates non-consumptive effects in a disease-impacted rocky shore food web. Oecologia , 191, 945-956.

Murray, D.L., Roth, J.D. \& Wirsing, A.J. (2004). Predation risk avoidance by terrestrial amphibians: the role of prey experience and vulnerability to native and exotic predators. Ethology, 110, $635-647$.

Nelson, M.E. \& Mech, L.D. (1991). Wolf predation risk associated with white-tailed deer movements. Can. J. Zool ., 69, 2696-2699.

Nicholson, K.L., Milleret, C., Månsson, J. \& Sand, H. (2014). Testing the risk of predation hypothesis: the influence of recolonizing wolves on habitat use by moose. Oecologia, 176, 69-80. 
Olsson, J. \& Eklöv, P. (2005). Habitat structure, feeding mode and morphological reversibility: factors influencing phenotypic plasticity in perch.Evol. Ecol. Res., 7, 1109-1123.

Orrock, J.L., Preisser, E.L., Grabowski, J.H. \& Trussell, G.C. (2013). The cost of safety: refuges increase the impact of predation risk in aquatic systems.Ecology , 94, 573-579.

Peacor, S.D. \& Werner, E.E. (2001). The contribution of trait-mediated indirect effects to the net effects of a predator. Proc. Natl. Acad. Sci. USA ., 98, 3904-3908.

Pokallus, J.W. \& Pauli, J.N. (2016). Predation shapes the movement of a well-defended species, the North American porcupine, even when nutritionally stressed.Behav. Ecol., 27, 470-475.

Post, E., Peterson, R.O., Stenseth, N.C. \& McLaren, B.E. (1999). Ecosystem consequences of wolf behavioral response to climate. Nature , 401, 905-907.

Preisser, E.L., Bolnick, D.I. \& Grabowski, J.H. (2009). Resource dynamics influence the strength of non-consumptive predator effects on prey. Ecol. Lett ., 12, 315-323.

Preisser, E.L., Orrock, J.L., \& Schmitz, O.J. (2007). Predator hunting mode and habitat domain alter nonconsumptive effects in predator-prey interactions.Ecology , 88, 2744-51.

Preisser, E.L., Bolnick, D.I., \& Benard, M.F. (2005) Scared to death? The effects of intimidation and consumption in predator-prey interactions. Ecology , 86, 501-509.

Prugh, L.R., Sivy, K.J., Mahoney, P.J., Ganz, T.R., Ditmer, M.A., van de Kerk, M. et al. (2019).

Designing studies of predation risk for improved inference in carnivore-ungulate systems. Biol. Cons., 232, 194-207.

Prugh, L.R. \& Golden, D. (2014). Does moonlight increase predation risk? Meta-analysis reveals divergent responses of nocturnal mammals to lunar cycles.J. Anim. Ecol., 83, 504-514.

Raveh, A. (2018). Ectoparasitism as a cost-incurring behavioural modifier in Allenby's gerbil (Gerbillus andersoni allenbyi). Ph.D. dissertation, Ben-Gurion University of the Negev, Be'er Sheva, Israel, pp. 1-72.

Raveh, A., Kotler, B.P., Abramsky, Z. \& Krasnov, B.R. (2011). Driven to distraction: detecting the hidden costs of flea parasitism through foraging behaviour in gerbils. Ecol. Lett., 14, 47-51.

Réale, D., Reader, S.M., Sol, D., McDougall, P.T. \& Dingemanse, N.J. (2007). Integrating animal temperament within ecology and evolution. Biol. Rev ., 82, 291-318.

Scherer, A.E., and Smee, D.L. (2016). A review of predator diet effects on prey defensive responses. Chemoecology, 26, 83-100.

Schmitz, O.J. (2017). Predator and prey functional traits: understanding the adaptive machinery driving predator-prey interactions. F1000Research, 6, 1767.

Schmitz, O.J. (2008). Effects of predator hunting mode on grassland ecosystem function.

Science, 319, 952-954.

Schmitz, O.J. (2007). Predator diversity and trophic interactions.Ecology , 88, 2415-2426. 
Schmitz, O. J. (2005). Behavior of predators and prey and links with population-level processes.

In Ecology of Predator-Prey Interactions (eds Barbosa, P., Castellanos, I.). Oxford University Press, New York, New York, USA, pp. 256-278.

Schmitz, O.J. \& Trussell, G.C. (2016). Multiple stressors, state-dependence and predation risk

- foraging trade-offs: toward a modern concept of trait-mediated indirect effects in communities and ecosystems. Curr. Opin. Behav. Sci., 12, 6-11.

Schmitz, O.J. \& Barton, B.T. (2014). Climate change effects on behavioral and physiological ecology of predator-prey interactions. Biol. Control , 75, 87-96.

Schmitz, O.J., Miller, J.R.B., Trainor, A.M. \& Abrahms, B. (2017a). Toward a community

ecology of landscapes: predicting multiple predator-prey interactions across geographic space. Ecology, 98, 2281-2292.

Schmitz, O.J., Buchkowski, R.W., Smith, J.R., Telhorst, M. \& Rosenblatt, A.E. (2017b).

Predator community composition is linked to soil carbon retention across a human use gradient. Ecology, 98, $1256-1265$.

Schmitz, O.J., Krivan, V., \& Ovadia, O. (2004). Trophic cascades: the primacy of trait-mediated indirect interactions. Ecol. Lett. 7, 153-163.

Sharpe, L.L., Joustra, A.S. \& Cheery, M.I. (2010). The presence of an avian co-forager reduces vigilance in a cooperative mammal. Biol. Lett ., 6, 475-477.

Sih, A. (1987). Prey refuges and predator-prey stability. Theor. Popul. Biol ., 31, 1-12.

Sih, A., Mathot, K.J., Moirón, M., Montiglio, P., Wolf, M. \& Dingemanse, N.J. (2015). Animal personality and state-behavior feedbacks: a review and guide for empiricists. Trend. Ecol. Evol., 30, 50-60.

Sih, A., Cote, J., Evans, M., Fogarty, S. \& Pruitt, J. (2012). Ecological implications of behavioral syndromes. Ecol. Lett ., 15, 278-289.

Sih, A., Bolnick, D.I., Luttbeg, B., Orrock, J.L., Peacor, S.D., Pintor, L.M. et al . (2010).

Predator-prey naïveté, antipredator behavior, and the ecology of predator invasions. Oikos, 119, 610-21.

Sih, A., Bell, A. \& Johnson, J.C. (2004). Behavioral syndromes: an ecological and evolutionary overview. Trends Ecol. Evol. , 19, 372-378.

Sih, A., Englund, G. \& Wooster, D. (1998). Emergent impacts of multiple predators on prey.

Trends Ecol. Evol. , 13, 350-355.

Sinclair, A.R.E. \& Arcese, P. (1995). Population consequences of predation-sensitive foraging:

the Serengeti wildebeest. Ecology , 76, 882-891.

Smith, J.A., Donadio, E., Pauli, J.N., Sheriff, M.J. \& Middleton, A.D. (2019). Integrating

temporal refugia into landscapes of fear: prey exploit predator downtimes to forage in risky places. Oecologia, 189, 883-890.

Thaker, M., Vanak, A.T., Owen, C.R., Ogden, M.B., Niemann, S.M. \& Slotow, R. (2011). 
Minimizing predation risk in a landscape of multiple predators: effects on the spatial distribution of African ungulates. Ecology, 92, 398-407.

Tollrian, R., and Harvell, C.D. (1999). The ecology and evolution of inducible defenses .

Princeton University Press, Princeton, NJ, USA.

Trussell, G.C., Ewanchuk, P.J. \& Matassa, C.M. (2006). Habitat effects on the relative

importance of trait- and density-mediated indirect interactions.Ecol. Lett ., 9, 1245-1252.

Turner, A.M. \& Chislock, M.F. (2010). Blinded by the stink: nutrient enrichment impairs the perception of predation risk by freshwater snails. Ecol. Appl ., 20, 2089-2095.

Valeix, M., Loveridge, A.J., Chamaillé-Jammes, S., Davidson, Z., Murindagomo, F., Fritz, H. et al. (2009). Behavioral adjustments of African herbivores to predation risk by lions:

spatiotemporal variations influence habitat use. Ecology, 90, 23-30.

Wallace, B.C., Lajeunesse, M.J., Dietz, G., Dahabreh, I.J., Trikalinos, T.A., Schmid, C.H. et al . (2017). OpenMEE: Intuitive, open-source software for meta-analysis in ecology and evolutionary biology. Methods Ecol. Evol., 8, 941-947.

Ward, A.J.W. \& Mehner, T. (2010). Multimodal mixed messages: the use of multiple cues

allows greater accuracy in social recognition and predator detection decisions in the mosquitofish, Gambusia holbrooki. Behav. Ecol., 21, 1315-1320.

Weissburg, M. \& Beauvais, J. (2015). The smell of success: the amount of prey consumed by predators determines the strength and range of cascading non-consumptive effects. Peer $J, 3$, e1426.

Werner, E.E. \& Peacor, S.D. (2003). A review of trait-mediated indirect interactions in ecological communities. Ecology , 84, 1083-1100.

Weissburg, M., Smee, D.L. \& Ferner, M.C. (2014). The sensory ecology of nonconsumptive predator effects. Am. Nat., 184, 141-157.

Willems, E.P. \& Hill, R.A. (2009). Predator-specific landscapes of fear and resource distribution: effects on spatial range use. Ecology , 90, 546-555.

Winandy, L. \& Denoël, M. (2015). The aggressive personality of an introduced fish affects foraging behavior in a polymorphic newt. Behav. Ecol ., 26, 1528-1536.

Wirsing, A.J. \& Heithaus, M.R. (2014). Accounting for individual behavioural variation in studies of habitat selection. J. Anim. Ecol ., 83, 319-321.

Wirsing, A.J. \& Ripple, W.J. (2011). A comparison of shark and wolf research reveals similar behavioral responses by prey. Front. Ecol. Environ ., 9, 335-341.

Wirsing, A.J. \& Heithaus, M.R. (2009). Olive-headed sea snakesDisteria major shift seagrass microhabitats to avoid shark predation. Mar. Ecol. Prog. Ser ., 387, 287-293.

Wirsing, A.J., Cameron, K.E. \& Heithaus, M.R. (2010). Spatial responses to predators vary with prey escape mode. Anim. Behav ., 79, 531-537. 
Wirsing, A.J., Heithaus, M.R. \& Dill, L.M. (2007). Living on the edge: dugongs prefer to forage

in microhabitats that allow escape from rather than avoidance of predators. Anim. Behav., 74, 93-101.

Zvereva, E.L. \& Kozlov, M.V. (2016). The costs and effectiveness of chemical defenses in

herbivorous insects: a meta-analysis. Ecol. Monogr ., 86, 107-124.

\section{Figure Legends}

Fig. 1 . Flow chart, adapted from Figure 1 in Lima \& Dill (1990), conceptualizing the process by which direct and indirect non-consumptive predator effects (NCEs) may manifest. ( $a$ ) Phase one. Each point in space and time is characterized by some value of intrinsic predation risk, or danger, defined after Lank \& Ydenberg (2003) as the inherent probability that an individual will become a prey item given no, or a standard amount of, anti-predator investment. Danger may or may not be perceived; in the latter case, no NCE will precipitate from the danger cue in question. $(b)$ Phase two. Given that the forager perceives risk cues, does it respond? Danger that is perceived may nevertheless fail to elicit a response of sufficient magnitude to trigger a NCE. Though not the focus of this review, prey individuals that do respond to perceived danger may experience stress, which may in turn affect fitness and consequently lead to risk effects. Furthermore, prey individuals that perceive danger may seek to manage their risk of predation through behavioral modifications, whose costs in terms of time and energy determine the magnitude of any associated risk effects. $(c)$ Phase three. Given that the forager responds to the cues, does the response induce an indirect interaction? Risk effects flowing from predator-induced stress and risk management can reduce prey population size and, in turn, trigger indirect interactions if changes to prey abundance affect other members of the community. The nature and strength of predator-induced risk management by prey can also determine whether and how other species in the community are affected indirectly; namely, if additional species are impacted by prey risk management, then NCEs can propagate through communities in the form of indirect interactions that are transmitted by prey behavior.

Fig. 2 . Observed (solid arrows) and hypothesized (dashed arrows) relationships between gray wolves (Canis lupus) and two sympatric ungulates - mule deer (Odocoileus hemionus) and white-tailed deer (O. virginianus ) - in areas of eastern Washington, USA, located outside $(a, c)$ and inside $(b, d)$ wolf pack territories. Non-consumptive effects of wolves on prey behavior (relative to wolf-free sites; $a$ ) are depicted in $b$, whereas $c$ and $d$ display baseline and wolf-influenced tropic relationships between the herbivores and the plants they target, respectively. Increasing effect size corresponds with arrow thickness. Mule and white-tailed deer are morphologically similar but have different running gaits (Lingle 1993). When threatened, mule deer flee by stotting, a bounding gait that limits speed on flat ground but facilitates navigation of uneven terrain and obstacles. White-tailed deer flee danger by galloping, a swift means of moving over gentle terrain that is less effective where the ground is more sloped or broken. This disparity explains differences in the space use of these two deer species that emerge when they are exposed to the risk from wolf predation during phase two ( $b$ versus $a)$. Working in a system in eastern Washington, USA, Dellinger et al . (2019) found that wolf presence elicited elevated use of sloped terrain by mule deer ( $b$; heavy arrow), presumably because the uneven ground characterizing these uplands confers an advantage to bounding prey seeking to escape coursing wolves. White-tailed deer space use differed comparatively little as a function of wolf presence, with individuals exposed to wolf risk manifesting small-scale shifts within their home ranges toward flat ground and roads that actually led to increased overlap with wolves ( $b$; thin arrow). By inference, white-tailed deer were able to manage risk 'in place' because of spatial synchrony between the effectiveness of their galloping means of escape and the space use pattern of their coursing predator. Notably, this form of risk management is expected whenever the safety benefits of matching predator distribution that accrue from escape facilitation outweigh the costs associated with elevated encounter probability (Lima 1992). These divergent anti-predator responses raise the possibility of recolonizing wolves triggering prey-specific indirect NCEs on plants during phase three ( $c$ versus $d$ ). In this ecosystem, mule and white-tailed deer exhibit considerable dietary overlap, though mule deer rely more heavily on upland shrubs (e.g., serviceberry;Amelanchier spp), and white-tailed deer exploit lowland riparian vegetation (e.g., willow; Salix spp.) to a greater degree (A. Craig, unpublished 
data ). Given that they elicit broad-scale spatial shifts by mule deer, wolves may dampen the impact of mule deer on lowland plant species ( $d$; thin dashed arrow) while strengthening this species' effects on upland plants growing in areas with steeper slopes ( $d$; thick dashed arrow). By contrast, the absence of a strong spatial response by white-tailed deer in areas occupied by wolf packs suggests that wolves may have modest and localized (i.e., within existing home ranges) indirect effects on the plants exploited by this deer species (similarity in the thickness of the solid and dashed arrows in $c$ and $d$ ).

Fig. 3 . Observed (solid arrows) and hypothesized (dashed arrows) relationships between tiger sharks ( $G a$ leocerdo cuvier ), their air-breathing prey - dugongs (Dugong dugon), dolphins (Tursiops cf. aduncus ), green turtles (Chelonia mydas), sea snakes (Disteria major; not pictured), pied cormorants (Phalacrocorax varius ) - omnivorous fish (Pelates octolineatus ), and seagrasses within shallow ( $<4.5 \mathrm{~m}$ water depth) habitats in Shark Bay, Western Australia. Species interactions are depicted during times when tiger sharks are present and absent from the bay, and interaction effect sizes correspond with arrow thickness. When tiger sharks are present, they preferentially spend time over shallow banks (Heithaus et al . 2002). Within these shallow habitats, they spend more time over bank edges compared to interior areas of banks (Heithaus et al . 2006). Non-consumptive direct effects of sharks on prey behavior (phase two) are black lines, whereas indirect relationships between tiger shark prey and lower trophic levels are gray lines (phase three). Dugongs (Wirsing et al . 2007), cormorants (Heithaus et al . 2009), dolphins (Heithaus \& Dill 2006), and sea snakes (Wirsing \& Heithaus 2009) distribute themselves between edge and interior portions (microhabitats) of shallow banks roughly proportional to food abundance when tiger sharks are absent. When sharks are present, by contrast, these species, along with green turtles (Heithaus et al . 2007), shift among the two microhabitats to enhance safety. Their spatial shifts during phase two, however, are based on species-specific escape tactics. Green turtles, dugongs, and dolphins escape through sub-surface flight and rely on maneuverability that is constrained over interior portions of banks. Accordingly, these species move into bank edges when tiger sharks are present to facilitate escape even at the cost of higher encounter rates with sharks (Heithaus et al . 2009). Conversely, sea snakes, which are unlikely to escape a tiger shark, and cormorants, which escape by flying away, shift toward interior areas of banks where shark encounters are minimized. For green turtles, habitat use is state-dependent with turtles in better condition selecting safer areas of banks with less food (Heithaus et al . 2007). Experimental studies of herbivory (Burkholder et al . 2013; Bessey et al . 2016) show that these spatial shifts cascade to seagrass communities during phase three.

Fig. 4 . Results of meta-analyses using two effect size metrics, Hedges' $d$ (black boxes) and log response ratios (gray boxes), to examine relationships between compromised energetic state and four dimensions of risk taking by prey under threat of predation: activity $(\mathrm{n}=30$ studies making 34 species-specific contrasts); exposure (versus use of a refuge; $\mathrm{n}=68$ studies making 71 contrasts); foraging investment (versus apprehension; $\mathrm{n}=37$ studies making 41 contrasts); isolation (versus grouping/shoaling; $\mathrm{n}=10$ studies presenting 10 contrasts). For each dimension, positive effect size values quantify the extent to which risk taking by energetically compromised prey individuals subjected to a predation threat exceeded that of conspecifics in better condition. Mean effect sizes and accompanying $95 \%$ confidence intervals were calculated using random effects models in OpenMEE ; confidence intervals not overlapping zero were considered to indicate significant effects.

Fig. 1

\section{Hosted file}

image1. emf available at https: //authorea.com/users/309328/articles/440276-the-context-dependenceof-non-consumptive-predator-effects

Fig. 2 


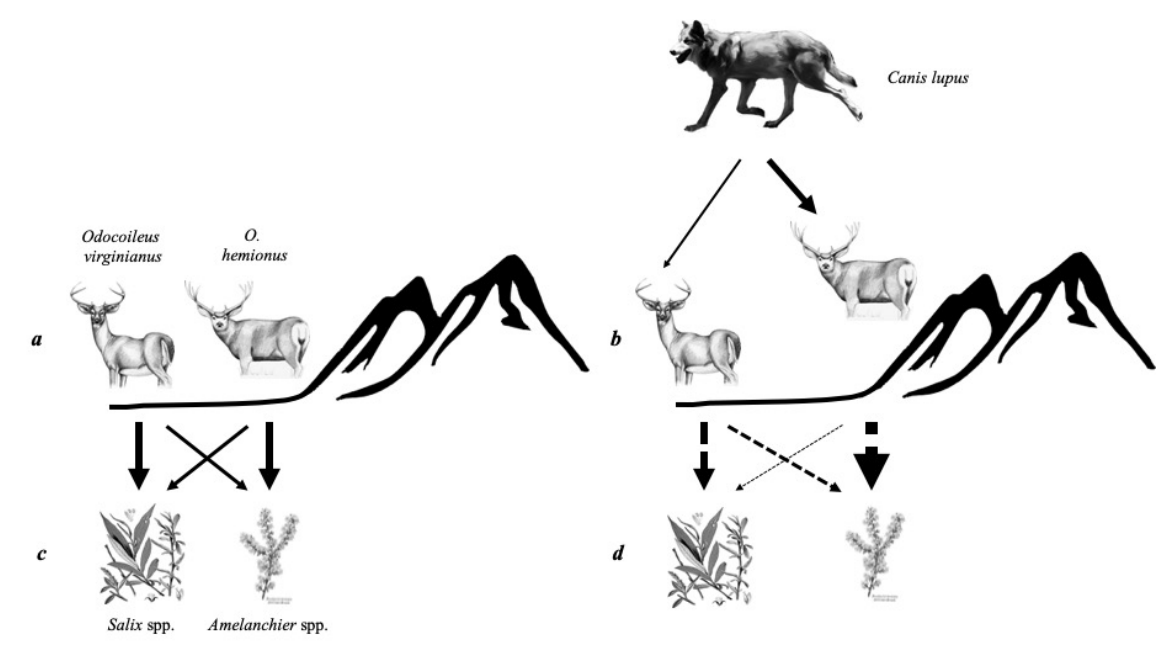

Fig. 3

\section{Hosted file}

image3.emf available at https://authorea.com/users/309328/articles/440276-the-context-dependenceof-non-consumptive-predator-effects

Fig. 4

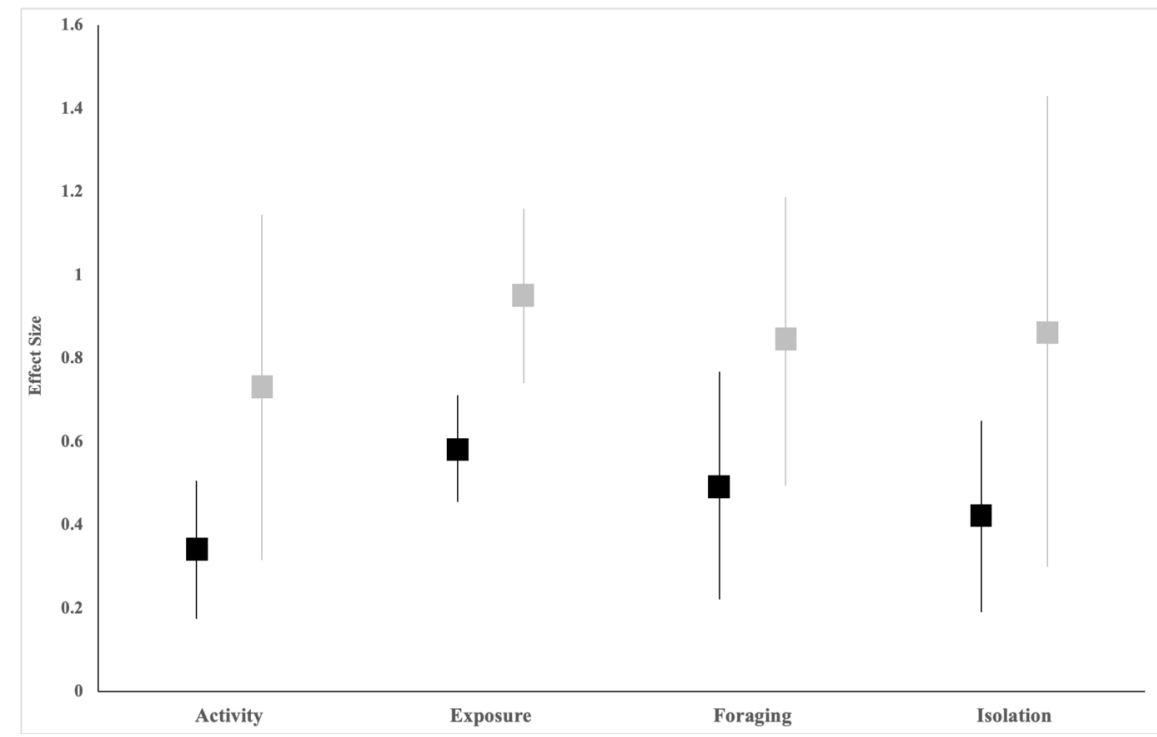

Box 1 : State dependent foraging games between gerbil prey and owl predators

The interaction of predator and prey is a state-dependent foraging game where the prey must manage risk using time allocation and vigilance (Brown 1999), and the predators must manage fear: as prey become more afraid, they become less catchable. The predator's tools include time allocation and derring-do; a more daring predator is more willing to risk injury in order to capture its prey (Brown et al . 2016). Here we focus on Allenby's gerbil (Gerbillus andersoni allenbyi), a nocturnal rodent of sand dunes in the Middle East, and its barn owl (Tyto alba) predator. Within an outdoor vivarium (17 x $34 \times 4.5 \mathrm{~m})$, it is possible to 
manipulate the energetic states, and subsequently quantify the foraging behavior, of both gerbils and owls (Kotleret al . 2004).

In theory, a forager should exploit depletable resource patches until the benefits of its harvest rate no longer exceed the sum of energetic, predation, and missed opportunity costs of foraging (Brown 1988). The food density at which this occurs is called the giving-up density (GUD) and is a behavioral indicator of foraging costs for that context. Energetic costs of foraging and risk factors should all lead to higher GUDs, and do so in gerbils (Kotler et al . 1991; Kotler et al . 1993). The predation cost is highly state-dependent as it equals predation risk multiplied by the survivor's fitness divided by the marginal value of the food. Hungry animals and those in a low state or with poor prospects should be less fearful and have lower GUDs.

In vivarium experiments, gerbils that received supplemental food, relative to those that did not, used food patches less intensively, had higher GUDs, and avoided risky open microhabitat (Kotler 1997; Kotleret al . 2004). These effects carried over into the subsequent night when no gerbils received supplemental food. Gerbils that had received supplemental food previously responded more strongly to owls than those that did not (Kotler 1997). These results show how a higher energetic state acts to magnify foraging costs and alter behaviors, ultimately leading to diminished risk taking during phase two.

Tracking gerbil foraging over the course of lunar cycles revealed the dynamic nature of risk management and feedbacks with state (Kotleret al . 2010). Starting at new moon, as the moon waxes, gerbils increased vigilance to counter the greater ease of predator encounter, and reduced their time allocation to limit their exposure to predators; they sacrificed state to buy safety. By full moon, the gerbils upped vigilance even more, but increased time foraging; they defended state to guard against starvation. As the moon waned, gerbils decreased vigilance and increased foraging time to rebuild state. By new moon, vigilance was at a minimum, and foraging time began to decline; state had been rebuilt in time for another cycle (Kotler et al . 2010).

Prey foraging behavior also depends on the interaction between the state of the prey and that of predator. Using vivarium experiments, Berger-Tal \& Kotler (2010) showed that hungry barn owls (Tyto alba) were 4-7 times more active than their satiated counterparts. Gerbils responded to this increase in predator activity by visiting fewer patches and leaving them at higher GUDs, but only when in high energetic state (Berger-Tal et al . 2010).

Predators, too, consider their state as well as that of their prey. Hungry owls, for example, showed derring-do by performing dangerous attack maneuvers (plunging into areas with stiff, spikey experimental shrubs) more than twice as often as well-fed conspecifics (Embaret al . 2014a). Moreover, owls choose between well-fed and hungry gerbils (Embar et al . 2014b). In spring when gerbils were reproductive, owls favored well-fed gerbils; in the summer when they were months away from breeding, owls favored hungry gerbils. That may seem odd, but well-fed gerbils are more active in spring when energy supports offspring, and hungry gerbils are more active than well-fed gerbils in summer when survivorship to the next reproductive season is paramount. Owls, when given the choice between gerbils with fleas and gerbils without, chose the more active flea-free gerbils (Raveh 2018). In all cases, then, owls sought more active prey.

In summary, foraging games between gerbils and their predators are contingent on environmental factors such as microhabitat and moon phase and biotic factors such as the energetic states of predators and prey. Prey manage risk, predators manage fear, and these actions feed back between the players and the environment throughout each night (Kotleret al . 2002), across moon phases (Kotler et al . 2002, 2010), and over the seasons (Kotler et al . 2004).

Box 2 : The timing of predation risk as an emergent driver of contingency in NCEs

How prey invest in defense at any given time during phase two (prey response to perceived risk) may depend on the temporal pattern of intrinsic predation risk. Namely, according to the risk allocation hypothesis, defensive investment should be greatest in response to transient pulses of high risk against a background of relative safety (given that periods during which safe feeding can occur should soon return), and reduced when 
pulses of safety occur against a background of elevated danger (Lima \& Bednekoff 1999). By implication, prey in systems where predation danger is highly punctuated may be able to compensate for heavy antipredator investment when predators are most active (and/or lethal) by feeding during periods of predator inactivity. For example, vicuñas (Vicugna vicugna) exploit puma (Puma concolor ) downtimes (during the day) to utilize their feeding grounds but avoid these densely-vegetated areas when low light levels and ample stalking cover combine to enhance puma lethality (Smith et al . 2019). Under these circumstances, demographic risk effects experienced by prey populations and the potential for prey to transmit indirect NCEs during phase three may be limited (Kohl et al . 2018).

To date, empirical support for the risk allocation hypothesis has been mixed (Ferrari et al . 2009), perhaps in part because prey condition in some assessments has been high enough to allow for continuous antipredator investment even when risk is chronic (Matassa \& Trussell 2014), or because some focal prey species were not given sufficient time to learn the risk regime (Moll et al . 2017). Our review offers an additional, non-mutually exclusive explanation. Namely, the temporal pattern of intrinsic risk experienced by a prey individual is an emergent outcome of the interaction between the properties (e.g., activity) of the predator(s) by which it is threatened and setting in which an encounter might take place. Moreover, as outlined earlier, the response of any prey individual/species to perceived intrinsic danger cues during phase two hinges on its own properties (e.g., escape tactics). Thus, proper quantification of the temporal pattern of risk and how prey should respond to perceived stimuli in any situation requires explicit consideration of each of these drivers of context dependence, as well as their interplay. It is possible that, lacking the capacity to be this comprehensive, some prior tests of the risk allocation hypothesis may have misrepresented the temporal pattern of risk. We view studies exploring this possibility as a fruitful line of inquiry. In the meantime, a recent investigation by Dröge et al . (2018) offers a path forward, at least in terms of accounting for predator properties. Namely, their ability to explain vigilance responses by African ungulates was greatest when immediate risk stimuli (predator proximity) were considered in relation to patterns of long-term risk associated specifically with the approaching predator species rather than the predator guild overall.

Box 3 : Methodology for the meta-analysis exploring contingent relationships between prey energetic state and risk taking

As the basis for our meta-analysis, we searched the literature using the bibliographic sources BIOSIS Previews, Google Scholar, and Web of Science using search terms for each engine were 'predator' OR 'predation' AND 'prey' AND 'risk taking' OR 'behavior' AND 'state' OR 'condition' OR 'hunger' OR 'nutrition' OR 'food'. We then screened all resulting studies to ensure that they (i) manipulated prey state directly (e.g., via starvation or nutritional supplementation of individuals) or indirectly (e.g., by contrasting behavior of individuals in environments offering different amounts of food); (ii) exposed prey to direct (e.g., live or model predators) or indirect (different amounts of cover) predation risk cues; (iii) presented comparisons of some form of risk-taking behavior by prey individuals with divergent energetic states that were not confounded by differences with respect to development, experience/learning, parasite load, personality/temperament, reproductive state, sex, or size; and (iv) included means, measures of variance, and sample sizes required for calculating effect sizes. Separate experiments addressing different species within the same study were considered to be independent.

After filtering, our review of the literature yielded a total of 145 studies spanning a broad range of taxa and presenting 156 unambiguous, species-specific contrasts of risk-taking behavior manifested by prey individuals with disparate energetic states (see Appendix S1 in Supporting Information). The risk-taking behaviors addressed by these studies clustered into four categories, which we analyzed separately: activity $(\mathrm{n}=30$ studies making 34 species-specific contrasts); exposure ( $\mathrm{n}=68$ studies making 71 contrasts); foraging investment (at the expense of apprehension; $\mathrm{n}=37$ studies making 41 contrasts); and isolation (versus grouping/shoaling; $\mathrm{n}=10$ studies presenting 10 contrasts). For the studies quantifying prey activity (movement), response metrics included time spent active or latency to resume activity after exposure to a predation risk cue for individuals, as well as the proportion of individuals in a group engaged in activity. Risk-taking responses addressed by studies of exposure were either time spent or the proportion of individuals not hiding, outside 
of a refuge, or in a dangerous versus safe area/patch. Studies addressing foraging investment quantified several feeding behaviors expected to influence vulnerability to predation: namely, feeding motivation (attack distance or latency to feed), feeding time, giving-up densities (GUDS; with greater amounts of food consumed corresponding to heightened foraging activity), and the proportion of individuals feeding. Studies of isolation quantified risk taking in terms of group cohesion (e.g., nearest neighbor distance) or size. For each of these four dimensions of risk taking, we first scaled all measures such that higher values corresponded with increased risk taking. Then, we assessed the across-study effects of prey energetic state on risk taking using two effect size metrics: Hedges' $d$ (Hedges \& Olkin 1985) and $\log$ response ratios (lnRR, Hedges et $a l$. 1999). For Hedges' $d$, we interpreted effect sizes of 0.2 to be "small", 0.5 to be "medium", 0.8 to be "large", and any exceeding 1 to be "very large" (Gurevitch \& Hedges 1993). Estimates of both effect sizes were considered to be statistically significant if their $95 \%$ confidence intervals did not overlap zero. For each of the four dimensions of risk taking, we calculated mean effect sizes for each effect size metric using random effects models in OpenMEE (Wallace et al . 2017). We also tested for publication bias with Spearman's rank-order correlations; no test was significant (all p [?] 0.076), so we did not use funnel plots to remove outliers from any of our four sub-analyses (Begg \& Mazumdar 1994). Finally, our meta-analyses of activity, exposure, and foraging investment included a few papers presented behavioral contrasts of more than one species. Given that these contrasts may not have been independent (Gurevitch \& Hedges 1999), we conducted truncated meta-analyses for the three aforementioned risk-taking dimensions that included only one randomly-selected contrast from each study addressing multiple species. Owing to close agreement between our full and truncated analyses, we only present results from the full analyses below. 